\title{
Literatura e leitura em tempos de Internet
}

\author{
Nelly Novaes Coelho \\ Universidade de São Paulo
}

\begin{abstract}
RESUMO: O TEXTO PROPÕE UMA BREVE DISCUSSÃO A RESPEITO DA IMPORTÂNCIA DA PALAVRA, DA LITERATURA E DA LEITURA FRENTE ÀS NOVAS RELAÇÕES QUE SE ESTABELECEM NUM MUNDO PERMEADO PELAS NOVAS TECNOLOGIAS.
\end{abstract}

ABSTRACT: THE TEXT OFFERS A BRIEF DISCUSSION ON THE IMPORTANCE OF LITERATURE AND READING IN FRONT OF THE NEW RELATIONS ESTABLISHED IN A WORLD PERMEATED BY NEW TECHNOLOGIES.

PALAVRAS-CHAVE: LITERATURA - LEITURA - INTERNET KEY-WORDS: LITERATURE - READING - INTERNET 
ma cultura cyber está em vias de se expandir, mesmo que isso só possa ser detectado por alguns espíritos atentos. Trata-se de uma revolução radical que marca o surgimento da sociedade pós-industrial e que implica no nascimento de um novo pensamento. [...] A cultura cyber é simultaneamente destruição e gênese. Essa cultura se unirá com o mito fundador do conhecimento?

(Edgar Morin, 1998)

Esse é o nosso tempo. Conforme a síntese do lúcido sociólogo francês, este é um tempo de mutações radicais. Isto é, mudanças que atingem as raízes do Conhecimento e do Sistema herdados. Vivemos hoje numa encruzilhada entre o ocaso da Civilização herdada (ocidental, cristã, burguesa, liberal, patriarcal, progressista...) e a fermentação de uma nova Cultura (ainda indefinível em seu todo) que, com o tempo, engendrará uma Nova Ordem, uma Nova Civilização (cujas coordenadas definitivas ainda não podem ser previstas).

É esse o tempo de mutação que nos desafia a colaborarmos com as mudanças ou a resistirmos a elas. Desafio difícil de ser enfrentado, principalmente por aqueles que, direta ou indiretamente, estão ligados à Educação e à necessária reformulação dos processos de Ensino em crise. Difícil, porque a esfera da Educação se vê atingida por dois fenômenos contraditórios: o de sua tarefa educativa, como transmissora da Ordem e das Tradições a serem continuadas pelas novas gerações e, ao mesmo tempo, o de sua tarefa de transgressora da "ordem", pela necessidade de estimular as potencialidades dos novos, para que se engajem nas mudanças em processo na Sociedade e com o tempo, se tornem agentes da Nova Ordem a ser construída. Como se vê são tarefas contraditórias. Como conciliá-las? Eis o desafio.

Um dos caminhos é o de nos prepararmos para a nova leitura-de-mundo que as aceleradas transformações estão exigindo. Partindo do dado básico de que o ser humano é, por essência, um ser cultural (cultura que lhe é imposta pelo meio em que vive e a educação que recebe), é fácil compreendermos a importância que, em plena Era da Imagem, vem sendo dada à leitura de texto, na área da Educação. É a palavra, e não a imagem, que organiza o mundo (note-se que toda imagem precisa de um "texto" que a explique). É a palavra que nomeia as realidades e lhes dá forma. É, pois, urgente que se estimule o convívio das crianças e jovens com as diversas formas de literatura, vista esta 
para além do prazer da leitura, como expressão verbal de experiências humanas. Experiências, nas quais, Tradição e Inovação se confundem. Como a História nos mostra, a Evolução da Humanidade se deu sempre através do amálgama entre o legado tradicional e o fermento inovador. Ambos se manifestando sempre, e se perpetuando no tempo, através da Palavra.

Como a palavra de ordem, em nossos dias, é Conscientização, comecemos aqui por situar esse tema no momento de crise civilizacional em que vivemos. Uma nova cultura está sendo engendrada e obviamente atinge as próprias bases da Educação letrada, que sempre foi um dos fundamentos da Civilização que herdamos. Não se trata apenas de uma mera mudança de métodos pedagógicos ou de táticas didáticas, mas do próprio processo de formação mental/ cultural das novas gerações. Essa Nova Cultura se manifesta amplamente através dos mass-midia, como: predominância da Imagem sobre a Palavra; do Espetáculo sobre a Reflexão e o da Dispersão sobre a Concentração.

Diante desse fenômeno, múltiplas experiências vêm sendo feitas, com sucessos ou fracassos. O que nos cabe é prosseguir na busca, pois o nosso tempo está exigindo projetos, ações e experiências que contribuam para a urgente formação do "novo homem séc. XXI". Lembremos que essa vem sendo a multimilenar tarefa do Homem, a quem cabe dar continuidade à Vida, à Humanidade: criar Cultura, cujos valores servirão de base para a construção de uma Civilização. Esta, com o tempo, organiza-se em Sistema que, posto em prática, gera um Progresso que, gradativamente, leva o Sistema ao apogeu de seu domínio. Nesse momento, estará nascendo um novo homem (engendrado pelo Sistema que "deu certo" e se ultrapassou), o qual já não cabe nos limites já estratificados e se volta contra eles, impondo novos valores existenciais/culturais ainda desordenados. É esse o ciclo histórico vivido pela humanidade desde a pré-história. É nesse "tempo de mutação" (F. Capra) que estamos vivendo, neste limiar do século XXI.

Podemos dizer, metaforicamente, que vivemos no "olho do furacão", entre duas grandes forças que se chocam. De um lado, a brilhante/progressista Civilização Industrial herdada, cuja cultura de base (cristã/liberal/burguesa) já se deteriorou, mas cujo Sistema (político/econômico/social) ainda está vigente muito embora, já profundamente alterado em sua base inicial. De outro, uma Nova Cultura (idéias/valores humanos/interrogações/conhecimentos) que, caoticamente, está sendo engendrada e se impondo, mas que 
ainda está longe de se organizar em Sistema, ou melhor, em Nova Civilização (Cibernética?).

Neste ponto, voltamos ao tema desta "Literatura e leitura em tempos de Internet". É importante lembrar que, apesar de estarmos vivendo em plena Era da Imagem (governados pelas multimídia visuais) há uma verdade basilar que estava sendo esquecida, mas começa a ser redescoberta: o mundo real existe revestido pelo mundo da linguagem. "A Palavra cria o Real" (idéia base da Fenomenologia, a teoria do conhecimento atual). "O homem é um ser de linguagem" (Michel Foucault). "O que não é nomeado não existe” (Lacan). A Literatura é sempre uma experiência de vida transformada em Palavra. Toda Imagem precisa de um Texto, para ser reconhecida como "algo". Enfim, o poder da palavra vem sendo redescoberto, como fator-chave na construção de uma Nova Educação.

O grande desafio a ser enfrentado pela Escola em crise está, hoje, no confronto entre o atual império da imagem (o cyberespaço) e o inesgotável poder construtor/ordenador da palavra (o mundo letrado, o livro). Em busca de novos paradigmas e nova instrumentalização, a Escola (a Cultura) se vê dividida entre a urgente redescoberta da Leitura e da Literatura (os grandes agentes de formação das mentes) e o fantástico meio de comunicação cibernética: a Internet, que veio para ficar.

Não há duvida de que, com a invenção do Computador, o mundo entrou na Era Digital (a da "cultura cyber" de que fala E. Morin), cuja "varinha mágica" (como a dos contos de fadas) é a Internet, poderosa mídia interativa, que permite ao usuário o acesso à informação numa escala planetária, nunca antes atingida. E mais, permitindo-lhe interagir dinamicamente com o Texto/Mensagem, explorando-o em vários sentidos, recriando-os, questionando-os etc. Crianças, jovens, adultos e idosos, de todas as etnias e regiões do globo, vivem hoje "plugados", acessando blogs, orkuts, googles, e-mails, e-books... Alguns deles, usando o Progresso para o Mal, transformam-se em piratas do cyberespaço, como "hackers"... Há toda uma revolução cultural em processo.

Incorporar esse instrumental mediático em seus novos projetos de Educação e Ensino é, sem dúvida, um dos grandes desafios enfrentados pela Reforma Educacional. Desafio que resulta do ainda precário sistema de interação existente entre o objeto básico de ensino (Língua e Literatura) e o novo instrumental (Internet). E obviamente uma nova formação docente. 
Sabe-se que a Crise do Ensino não será solucionada apenas com a inclusão do Computador na sala de aula, conectado à Internet. Faz-se urgente, uma nova reestruturação do Saber. É a nova Esfinge que desafia educadores e técnicos programadores: "Decifra-me! Ou eu te anulo!" Como integrar, num projeto de formação humana (para além da mera diversão ou de acesso à informação), o Conhecimento e o Instrumental? É o que vem sendo tentado por educadores e especialistas nas multimídias e que já preocupava, quarenta anos atrás, a socióloga americana, Margaret Mead:

Chegamos ao ponto em que temos de educar as pessoas naquilo que ninguém sabia ontem, e prepará-las para aquilo que ninguém sabe ainda, mas que alguns terão que saber amanhã. (1968)

A solução ou resposta definitiva do problema está longe de ser alcançada. O que nos cabe é tentarmos soluções provisórias (que talvez acabem se mostrando definitivas!). Cada qual dentro das circunstâncias que a vida lhe oferece. É ainda cedo para prevermos qual será a verdadeira influência desse novo instrumental cibernético sobre a formação das novas gerações. O que já se pode dizer, pois salta à vista, é que ele está provocando a aceleração do rimo vital (rapidez de percepção e raciocínio, agudez visual, facilidade para estabelecer conexões entre diferentes fatores etc.) É o tempo bumano (que é lento, pois segue o ritmo da Natureza) sendo gradativamente modificado pelo tempo da máquina (que é cada vez mais acelerado). Isso é bom? É ruim? Impossível concluir por enquanto.

Ainda no âmbito desse fenômeno surge um problema que tende a se aprofundar em gravidade: a ameaça de degradação ou deterioração da Lingua Portuguesa, pelo uso sistemático do dialeto "internetês", palavras reduzidas a poucas letras ou signos, que tornam o texto incompreensível por quem não souber decifrá-las. Se é verdade que tal "dialeto" se faz necessário devido às condições materiais do instrumental (espaço reduzido, velocidade exigida, necessidade de síntese etc.), não é menos verdade que a Nova Educação precisa, urgentemente, criar um "anticorpos” a essa ameaça à Língua Portuguesa, incentivando os estudos lingüísticos e literários. E, obviamente, começando pela formação dos mais novos, cuja entrada no mundo da cultura tem, na Literatura Infantil/Juvenil, um dos meios mais prazerosos e fecundos. 
Como estamos vivendo uma profunda revolução cultural (na qual a Internet, por ser atualmente o grande meio de comunicação, desempenha um papel decisivo) é urgente que se atente para o fato de que a Língua materna é o elemento primordial, na construção da Identidade de um povo. Como lembra Octavio Paz:

Quando uma civilização entra em decadência, a primeira coisa que apodrece é a Língua.

É essa, a grande ameaça que se pressente no uso intensivo da Internet (ou no convívio alienado com o mundo virtual da Imagem), se o jovem usuário, ainda em formação, não receber o "antídoto" essencial: o domínio da Palavra, o conhecimento da dinâmica da Língua Portuguesa (uma das mais ricas e expressivas línguas do mundo). É urgente que os novos a descubram, como algo vivo (que os identifica como "cidadãos brasileiros"), e convivam com a Literatura, como a grande arte, cuja matéria-prima é a palavra, e que tem como objeto infinitas experiências de vida. Como disse Guimarães Rosa ao seu tradutor, Gunther Lorenz:

[...] A Linguagem e a Vida são uma coisa só [...] Quem não fizer do idioma o espelho de sua personalidade, não vive. [...] O idioma é a única porta para o infinito, mas infelizmente está oculto sob montanhas de cinzas.

Cabe a cada um revolver as cinzas e descobrir a "porta" oculta...

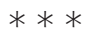

\section{Referências Bibliográficas}

LORENZ, Gunter. "Diálogo com Guimarães Rosa”. In COUTINHO, Eduardo. Org. Guimarães Rosa. Rio de Janeiro: Civilização Brasileira/INL, 1983.

MEAD, Margaret. L'adolescente in una società primitiva. Firenze: Ed. Universitária, 1968. MORIN, Edgar. Articuler les savoirs. Paris: Centre National de Documentation Pedagogique, 1998.

PAZ, Octavio. El signo y el garabato. México: Joaquim Moritz, 1975. 